\title{
Effect of B complex vitamins on life quality and neuropathic pain intensity in patients undergoing hemodialysis
}

\author{
José Eduardo Nogueira Forni', Ana Carolina Rodrigues², Amanda Fidalgo Lima ${ }^{3}$, \\ Bianca de Oliveira Lemos ${ }^{4}$, Beatriz Arid Rudnick ${ }^{5}$, Gabriela Modulo Molina ${ }^{6}$, \\ Narayana Silva Paiva ${ }^{7}$
}

${ }^{1}$ Assistant Professor, 2,3,4,5,6,7 Medical Student, Department of Orthopedics and Traumatology, Faculdade de Medicina de São José do Rio Preto, São José do Rio Preto, São Paulo, Brazil

A B S T R A C T

Background: Neuropathic pain (NP) is characterized by chronic pain with a generally strong intensity that leads to limitations regarding activities of daily living. Aims and Objectives: The aim of the study was to investigate the effect of B complex vitamins on NP intensity and life quality in patients undergoing hemodialysis. Materials and Methods: A randomized controlled double-blind clinical trial was conducted among hemodialysis patients with clinical diagnosis of NP randomly allocated to two groups: A (gabapentin) and B (B vitamins). DN4, visual analog scale, and Kidney Disease Quality of Life-Short Form questionnaire were used to identify NP, measure pain intensity, and assess quality of life, respectively. Results: A significant reduction in pain occurred after treatment with gabapentin $(P=0.003)$. In the $B$ group, the reduction of pain went from a mean of 7.27 to 5.09 after treatment $(P=0.056)$. In the $A$ group, a significantly poorer quality of life was reported after treatment in the social relations domain $(P=0.010)$. A significant improvement in quality of life and environment domains $(\mathrm{P}=0.025$ and 0.049 , respectively) was reported after use of $\mathrm{B}$ vitamins. Conclusion: These findings demonstrate that B complex vitamins for the treatment of NP in hemodialysis patients should be investigated further, as this form of treatment contributed to a reduction in pain intensity and suffering with no side effects and at low cost.

Key words: Chronic pain; Chronic renal failure; Drug therapy; Pain; Quality of life

\section{Access this article online}

Website:

http://nepjol.info/index.php/AJMS DOI: 10.3126/ajms.v13i3.39472

E-ISSN: 2091-0576

P-ISSN: 2467-9100

Copyright (c) 2022 Asian Journal of Medical Sciences

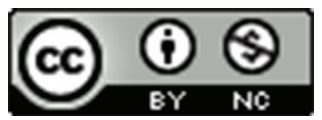

This work is licensed under a Creative Commons Attribution-NonCommercial 4.0 International License.

\section{INTRODUCTION}

Neuropathic pain (NP) is characterized by chronic pain with a generally strong intensity that leads to limitations regarding activities of daily living and a significant reduction in quality of life. Such pain is related to an injury or disease that affects the somatosensory system and occurs independently of any external nociceptive stimulus, leading to chronicity. It is estimated that one out of five cases of chronic pain is due to NP, affecting $6.9-10 \%$ of the population. ${ }^{1}$ Despite the efforts of health-care providers, NP is believed to be underdiagnosed, as there is no specific instrument for its diagnosis. Metabolic diseases, such as diabetes, often lead to polyneuropathy, which can manifest in different ways, such as pruritus, numbness, and hyperpathia, and can become chronic when there is no diagnosis or effective clinical treatment. ${ }^{2,3}$

The main etiologies of chronic kidney disease (CKD) are hypertension and diabetes mellitus (DM). Type 1 and type 2 DM lead to CKD in $30 \%$ and $20 \%$ of cases, respectively. ${ }^{4}$ Therefore, the occurrence of NP in patients undergoing hemodialysis is expected but underdiagnosed.

The most widely used drugs for the treatment of NP include gabapentin and pregabalina. ${ }^{5}$ However, both have side effects, such as sleepiness and intestinal constipation, and can interfere with activities of daily living, which are 
already compromised in patients with kidney failure. Thus, the possibility of treating NP with drugs that do not have such side effects would be of considerable assistance to these patients.

A study found an improvement in the intensity of NP in patients with diabetic polyneuropathy with the use of Vitamins B1, B6, and B12. ${ }^{6}$ The Vitamins B complex are a group of eight water-soluble vitamins with several functions in the human body. Vitamins $\mathrm{B}_{1}, \mathrm{~B}_{2}, \mathrm{~B}_{3}$, and biotin participate of the energy production; Vitamin $\mathrm{B}_{6}$ is fundamental for amino acid metabolism, and Vitamin $\mathrm{B}_{12}$ and folic acid facilitate steps required for cell division. ${ }^{7}$ Thiamine is required for normal functioning of the heart, muscles, and nerves, and its intake is beneficial in the treatment of certain metabolic disorders. ${ }^{8}$

The findings of Hakim et al., ${ }^{6}$ motivated the present study. The aim of which was to investigate the effects of B complex vitamins on NP intensity and quality of life in patients undergoing hemodialysis.

\section{Aims and objectives}

The aim of the study was to investigate the effects of B complex vitamins on NP intensity and quality of life in patients undergoing hemodialysis.

\section{MATERIALS AND METHODS}

A randomized, controlled, double-blind, and clinical trial was conducted at the Hemodialysis Unit of the Hospital de Base de São José do Rio Preto, in Brazil, South America, involving patients on dialysis with a clinical diagnosis of NP. Patients with mental incapacity and those who did not grant consent to participate in the study were excluded from the study.

This study received approval from the Human Research Ethics Committee of the Faculdade de Medicina de São José do Rio Preto (certificate number: 12779019.2.0000.5415). Written informed consent was obtained from all study participants. All procedures involving human participants were in accordance with the ethical standards of the research committee and with the 1964 Helsinki Declaration and its later amendments or comparable ethical standards.

The participants were randomly allocated to two groups: A (gabapentin) and B (B vitamins). The control group received gabapentin (EMS, Indaiatuba, Brazil) at a dose of $300 \mathrm{mg} /$ day orally for 30 days. The study group received B complex vitamins (Merck SA, São Paulo, Brazil) at a dose of $5000 \mathrm{mg} /$ day (single pill) orally for 30 days.

The drugs were placed into bottles identified as Drug A and Drug B. Only the main investigator, who did not participate in the evaluations, knew what drug was in each bottle. The patients and evaluators were blinded to the contents of the bottles.

Data collection involved the use of questionnaires and a pain scale. The DN4 was used for the assessment of NP. This questionnaire is composed seven items addressing symptoms and three items related to the physical examination. ${ }^{9}, 10$ Each item is scored 1 point for an affirmative answer and zero for a negative answer. The total ranges from zero to 10 points, with scores of 4 or more points indicative of NP.

Quality of life was assessed using the Kidney Disease Quality of Life-Short-Form (KDQOL-SF ${ }^{\mathrm{TM}} 1.3$ ), which is a specific instrument addressing CKD applicable to patients undergoing some type of dialysis program. ${ }^{7}$ The instrument is self-administered and has 80 items divided into 19 scales and five domains (Overall quality of life, physical, psychological, social relations, and environment). ${ }^{11}$

Pain intensity was measured using the visual analog scale (VAS), which consists of a 10-cm line with "absence of pain" and "worse possible pain" printed at the two ends. The patient marks a point on the line corresponding to his/her current pain level, which is measured with a ruler from the lower extreme of the scale and expressed in centimeter.

Convenience sampling was used. The sample size was calculated considering the population of 400 patients under monthly care at the hemodialysis unit, a 95\% confidence interval and $8.55 \%$ margin of error, determining 99 patients.

\section{Statistical analysis}

Descriptive statistics were performed for the calculation of absolute frequencies, percentages, as well as measures of central tendency and dispersion. The KolmogorovSmirnov normality test was used the inferential analysis, followed by the paired t-test for the comparison of means between two dependent groups. Data analysis was performed with the aid of the Statistical Package for the Social Sciences, version $23.0,{ }^{12}$ and $\mathrm{P} \leq 0.05$ was considered indicative of statistical significance.

\section{RESULTS}

Figure 1 provides a flow diagram of the participants enrolled in this study. Ninety-nine patients undergoing hemodialysis were recruited, $29.3 \%(n=29)$ of whom had characteristics of NP. Among these individuals NP, 20 agreed to participate in the study and were randomly 
allocated to the $\mathrm{G}(\mathrm{n}=8)$ and $\mathrm{B}(\mathrm{n}=12)$ groups. During the course of the experiment, two patients from the A group withdrew from the study and one from the B group died. Thus, the final sample was composed of 17 patients (six in the A group and 11 in the B group).

Mean age of the patients with NP $(n=17)$ was $57.65 \pm 18.58$ years. The largest portions of the sample were women $(88.3 \%)$, heart patients $(52.9 \%)$, and individuals with diabetes $(41.1 \%)$, with a predominance of pain in the lower limbs (88.3\%) and low back (29.4\%) (Table 1). The mean duration of hemodialysis was $57.86 \pm 55.98$ months.

Regarding pain intensity measured using the VAS (Table 2), a significant reduction from a mean of 8.33 (strong) to 4.83 (weak) was found in the A group after treatment with gabapentin $(\mathrm{P}=0.003)$. In the $\mathrm{B}$ group, the reduction of

All subjects undergoing hemodialysis were recruited $(n=99)$



Figure 1: Flow diagram of the participants in the study. NP: Neuropathic pain

\begin{tabular}{|c|c|}
\hline Variables & n (\%) \\
\hline \multicolumn{2}{|l|}{ Sex } \\
\hline Female & $15(88.3)$ \\
\hline Male & $2(11.7)$ \\
\hline Diabetes & 7 (41.1) \\
\hline Heart disease & 9 (52.9) \\
\hline Dyslipidemia & $2(11.7)$ \\
\hline Rheumatism & $1(5.8)$ \\
\hline Depression & $2(11.7)$ \\
\hline \multicolumn{2}{|l|}{ Pain site } \\
\hline Head & $2(11.7)$ \\
\hline Upper limbs & $4(23.5)$ \\
\hline Low back & $5(29.4)$ \\
\hline Abdomen & $3(17.6)$ \\
\hline Hips & $2(11.7)$ \\
\hline Lower limbs & 15 (88.3) \\
\hline
\end{tabular}

pain went from a mean of 7.27 (strong) to 5.09 (moderate) after treatment with $\mathrm{B}$ complex vitamins, but this difference did not achieve statistical significance $(\mathrm{P}=0.056)$.

For the analysis of quality of life, Tables 3 and 4 display the results of the KDQOL-SF ${ }^{\mathrm{TM}}$ for patients in the $\mathrm{A}$ and $\mathrm{B}$ groups, respectively, before and after treatment. No significant differences were found in the overall, physical, psychological, or environment domains after treatment with gabapentin. In contrast, a significantly poorer quality of life was found regarding the social relations domain after treatment with this drug $(\mathrm{P}=0.010)$ (Table 3).

In the B group, no significant differences were found in the physical, psychological, or social relations domains after treatment with B complex vitamins. In contrast, a significant improvement in quality of life was reported after the use of $\mathrm{B}$ complex vitamins regarding the overall quality of life and environment domains $(\mathrm{P}=0.025$ and 0.049 , respectively) (Table 4).

\section{DISCUSSION}

The diagnosis of NP is complex due to the lack of a conclusive test. Questionnaires such as the DN4 and the Leeds Assessment of Neuropathic Symptoms and Signs pain scale combined with clinical findings can assist in the diagnosis. After the identification of NP, it is fundamental to assess the intensity of the pain using the visual analog scale and perform analgesia, as recommended by the World Health Organization. ${ }^{13}$ Treatment should be performed following the main international guidelines, which include the use of gabapentin or pregabalin combined with opiates. ${ }^{14}$ These drugs have side effects, such as sleepiness and intestinal constipation, especially in patients undergoing hemodialysis. Therefore, the possibility of treating NP with drugs that do not have such side effects would be of considerable assistance to these patients.

The treatment of pain in patients on hemodialysis is challenging, as diverse diseases are responsible for the emergence of pain, besides hemodialysis itself, which can cause chronic pain. The prevalence of pain in these patients ranges from $50 \%$ to $75 \%$; however, such individuals are undertreated due to a lack of knowledge on the part of the medical team. ${ }^{14}$ For adequate treatment, physicians must consider all modalities (nociceptive, neuropathic, and multimodal) with the aim of avoiding the non-control or partial control of the pain.

A multicenter prospective study assessed patients between 18 and 65 years of age with polyneuropathy caused by DM and other etiologies who received B complex vitamins 
Table 2: Intensity of neuropathic pain evaluated using VAS in patients undergoing hemodialysis before and after treatment with gabapentin (G group) and B complex vitamins (B group)

\begin{tabular}{|c|c|c|c|c|c|c|c|}
\hline \multirow[t]{2}{*}{ VAS } & \multicolumn{2}{|c|}{ Mean } & \multicolumn{2}{|c|}{ Median } & \multicolumn{2}{|c|}{ SD } & \multirow[t]{2}{*}{ P-value* } \\
\hline & Pre & Post & Pre & Post & Pre & Post & \\
\hline $\mathrm{G}$ group $(\mathrm{n}=6)$ & 8.33 & 4.83 & 9.00 & 4.50 & 1.75 & 1.94 & $0.003^{* *}$ \\
\hline B group $(n=11)$ & 7.27 & 5.09 & 8.00 & 7.00 & 2.87 & 3.73 & 0.056 \\
\hline
\end{tabular}

Table 3: Means for each quality of life domain on KDQOL-SF ${ }^{\mathrm{TM}}$ of patients on hemodialysis with neuropathic pain before and after treatment with gabapentin ( $\mathrm{G}$ group, $\mathrm{n}=6$ )

\begin{tabular}{lccc}
\hline Domains & Pre & Post & P-value* $^{*}$ \\
\hline Overall & $4.83 \pm 2.13$ & $6.16 \pm 2.56$ & 0.346 \\
Physical & $64.50 \pm 12.65$ & $76.00 \pm 15.25$ & 0.174 \\
Psychological & $27.00 \pm 11.08$ & $27.67 \pm 9.99$ & 0.810 \\
Social relations & $10.00 \pm 2.53$ & $7.33 \pm 1.21$ & $0.010^{* *}$ \\
Environment & $127.50 \pm 18.72$ & $137.00 \pm 32.29$ & 0.485 \\
\hline
\end{tabular}

*Paired t-test, **Significant difference, KDQOL-SF ${ }^{\mathrm{Tm}}:$ Kidney Disease Quality of Life-Short-Form

Table 4: Means for each quality of life domain on KDQOL-SF ${ }^{T M}$ of patients on hemodialysis with neuropathic pain before and after treatment with $B$ complex vitamins ( $B$ group, $n=11$ )

\begin{tabular}{lccc}
\hline Domains & Pre & Post & P-value $^{*}$ \\
\hline Overall & $6.18 \pm 2.32$ & $7.82 \pm 1.72$ & $0.025^{\star *}$ \\
Physical & $70.27 \pm 20.20$ & $77.55 \pm 18.10$ & 0.074 \\
Psychological & $29.73 \pm 7.81$ & $29.36 \pm 10.30$ & 0.884 \\
Social relations & $9.18 \pm 2.71$ & $9.64 \pm 2.94$ & 0.884 \\
Environment & $134.36 \pm 22.77$ & $145.18 \pm 24.08$ & $0.049^{* *}$ \\
\hline
\end{tabular}

*Paired t-test, **Significant difference, KDOOL-SF ${ }^{\mathrm{TM}}$ : Kidney Disease Quality of Life-Short-Form

once a day for 12 weeks. ${ }^{6}$ The patients were submitted to evaluations after 14 days and then monthly. Significant improvements were found in numbness (55\%), acute pain $(64.7 \%)$, burning sensations $(80.6 \%)$, and paresthesia $(61.3 \%)$, demonstrating the effectiveness of Vitamin B in the treatment of NP, which occurs through the different modes of action of $\mathrm{B}$ complex vitamins.

In the present study, we compared the results of B complex vitamins in patients on hemodialysis with NP to those achieved with gabapentin, which is the first line of treatment for NP in international guidelines. A significant improvement was found with gabapentin, with a reduction in the VAS score from 8.33 to 4.83. In the B group, which received $\mathrm{B}$ complex vitamins, the reduction in the VAS score was from 7.27 (strong intensity) to 5.09 (moderate intensity). Although this reduction did not achieve statistical significance, it was a clinically important improvement, as it contributed toward alleviating human suffering with no side effects.
In the assessment of quality of life, significant improvements were found in the overall quality of life and environment domains in the patients who took B complex vitamins. In contrast, the patients who took gabapentin reported a significant worsening in the social relations domain after treatment with this drug, possibly due to the side effect of sleepiness, which may have exerted a negative impact on quality of life in this group. ${ }^{14}$ Gabapentinoids should be introduced at low doses and increased based on the need for pain control, as these patients have kidney failure and the side effects can lower their quality of life. On the other hand, B complex vitamins have no side effects and are inexpensive, offering a satisfactory cost/benefit ratio for patients on hemodialysis with NP. ${ }^{15,16}$

The main limitation of the present study regard the small number of patients on hemodialysis with NP who agreed to medicinal treatment $(\mathrm{n}=20)$, which limits the possible inferences of the results. The study population was limited to 3 months of treatment at the hemodialysis unit of a regional reference center. Treatment with the drugs should have been longer to assess the possible side effects and improvements in both pain intensity and quality of life in patients undergoing hemodialysis.

\section{Limitations of the study}

In this study, the sample size was small and the observation time was short.

\section{CONCLUSION}

The use of B complex vitamins for the treatment of NP in patients undergoing hemodialysis should be investigated further, as this form of treatment contributed to a reduction in pain intensity and suffering in these patients with no side effects and at low cost.

\section{ACKNOWLEDGMENT}

The authors would like to thank Débora M. Casassanta, MD, for institutional support, and Prof. Renato B. Araujo, $\mathrm{PhD}$, for assistance with data analysis and manuscript preparation. 


\section{REFERENCES}

1. van Hecke O, Austin SK, Khan RA, Smith BH and Torrance N. Neuropathic pain in the general population: A systematic review of epidemiological studies. Pain. 2014;155(4):654-662.

https://doi.org/10.1016/j.pain.2013.11.013

2. Posso IP, Palmeira CC and Vieira EB. Neurophatic pain epidemiology. Rev Dor. 2016;17 Suppl 1:11-14.

https://doi.org/10.5935/1806-0013.20160039

3. Vilar S, Castillo JM, Martínez PV, Reina M and Pabón M. Therapeutic alternatives in painful diabetic neuropathy: A meta-analysis of randomized controlled trials. Korean J Pain. 2018;31(4):253-260.

https://doi.org/10.3344/kjp.2018.31.4.253

4. Romão Junior JE. Chronic kidney disease: definition, epidemiology and classification Braz J Nephrol. 2004;26 Suppl 1:1-3.

5. Finnerup NB, Attal N, Haroutounian S, McNicol E, Baron R, Dworkin RG, et al. Pharmacotherapy for neuropathic pain in adults: A systematic review and meta-analysis. Lancet Neurol. 2015;14(2):162-167.

https://doi.org/10.1016/S1474-4422(14)70251-0

6. Hakim M, Kurniani N, Pinzon RT, Tugasworo D, Basuki M, Haddani $\mathrm{H}$, et al. Management of peripheral neuropathy symptoms with a fixed dose combination of high-dose vitamin B1, B6 and B12: A 12-week prospective non-interventional study in Indonesia. Asian J Med Sci. 2018;9(1):32-40.

https://doi.org/10.3126/ajms.v9i1.18510

7. Raval $A D$, Thakker $D$, Rangoonwala $A N$, Gor $D$ and Walia R. Vitamin B and its derivatives for diabetic kidney disease. Cochrane Database Syst Rev. 2015;1:CD009403.

https://doi.org/10.1002/14651858.CD009403.pub2

8. Thornalley PJ, Babaei-Jadidi R, Al Ali H, Rabbani $\mathrm{N}$, Antonysunil A, Larkin J, et al. High prevalence of low plasma thiamine concentration in diabetes linked to a marker of vascular disease. Diabetologia. 2007;50(10):2164-2170.

https://doi.org/10.1007/s00125-007-0771-4

9. Santos JG, Brito JO, de Andrade DC, Kaziyama VM, Ferreira KA, Souza I, et al. Translation to Portuguese and validation of the douleur neuropathique 4 questionnaire. J Pain. 2010;11(5):484-490.

https://doi.org/10.1016/j.jpain.2009.09.014

10. Bouhassira D, Attal N, Alchaar H, Boureau F, Brochet B, Bruxelle J, et al. Comparison of pain syndromes associated with nervous or somatic lesions and development of a new neuropathic pain diagnostic questionnaire (DN4). Pain. 2005;114(1-2):29-36. https://doi.org/10.1016/j.pain.2004.12.010

11. Hays RD, Kallich JD, Mapes DL, Coons SJ, Amin N, Carter WB, et al. Kidney Disease Quality of Life-Short form (KDQOL-SF ${ }^{\text {TM }}$ ), Version 1.3: A Manual for Use and Scoring. Santa Monica, CA, USA: RAND; 1997.

12. IBM Corp. IBM SPSS Statistics for Windows, Version 23.0. Armonk, New York: IBM Corp; 2015.

13. Organización Mundial de La Salud. Alivio del Dolor en el Cancer. Ginebra: Organización Mundial de La Salud; 1987.

14. Raina R, Krishanappa $V$ and Gupta M. Management of pain in end-stage renal patients: Short review. Hemodial Int. 2018;22(3):290-296. https://doi.org/doi:10.1111/hdi.12622

15. Quintero GC. Review about gabapentin misuse, interactions, contraindications and side effects. J Exp Pharmacol. 2017;9:13-21.

https://doi.org/10.2147/jep.s124391

16. Finnerup NB, Sindrup $\mathrm{SH}$ and Jensen TS. The evidence for pharmacological treatment of neuropathic pain. Pain. 2010;150(3):573-581.

https://doi.org/10.1016/j.pain.2010.06.019

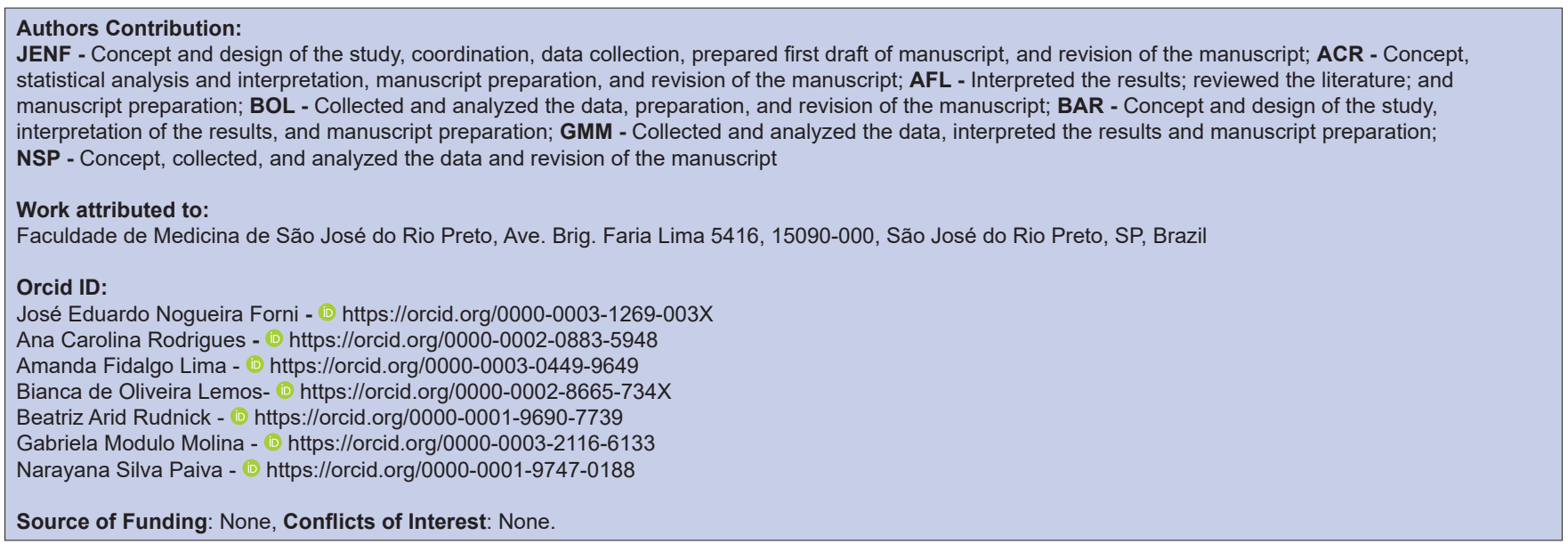

